\title{
PARÂMETROS GENÉTICOS EM PROGÊNIES DE POLINIZAÇÃO LIVRE DE ACEROLA ${ }^{1}$
}

\author{
JOÃO RODRIGUES DE PAIVA², WALDELICE OLIVEIRA DE PAIVA ${ }^{3}$, \\ EVERTON RABELO CORDEIRO e HASSAN SABRY NETO ${ }^{4}$
}

\begin{abstract}
RESUMO - A acerola (Malpighia emarginata D.C.) é uma cultura que vem despertando grande interesse por parte de consumidores, produtores, industriais e exportadores, dado o seu alto teor de vitamina C. No Brasil, não existem variedades recomendadas para o plantio comercial; por esta razão, os dados de produção são muito variáveis. O presente trabalho visa estimar e interpretar geneticamente a porção de variabilidade existente quanto a alguns caracteres, em uma população de plântulas de aceroleira obtidas de sementes, originalmente selecionadas em plantio comercial no Estado do Ceará. O experimento foi instalado no local definitivo em abril/96, na Estação Experimental da Embrapa-Centro Nacional de Pesquisa de Agroindústria Tropical (CNPAT), no município de Pacajus, CE, sob arranjo experimental de blocos casualizados, com 62 tratamentos, três repetições e quatro plantas por parcelas, no espaçamento de $4 \mathrm{~m}$ entre linhas e $3 \mathrm{~m}$ entre plantas. Os tratamentos são constituídos por progênies de polinização livre. No primeiro ano de idade das plantas, a maioria das progênies já tinha frutificado, sendo que a proporção de florescimento era menor do que a frutificação no período de avaliação. Pelas estimativas dos coeficientes de herdabilidade dos caracteres, pode-se afirmar que a seleção de progênies resultará em ganhos superiores em relação à seleção de plantas. Os índices $b_{1}$ e $b_{2}$, que quantificam a relação da variação genética em face da variação ambiental entre e dentro de progênies, respectivamente, revelam uma condição favorável à seleção dentro de progênies.
\end{abstract}

Termos para indexação: Malpighia emarginata, variabilidade genética, seleção fenotípica.

\section{GENETIC PARAMETERS IN OPEN POLLINATION PROGENIES OF THE ACEROLA}

ABSTRACT - Acerola (Malpighia emarginata D.C.), a typical tropical crop, has shown excellent adaptation in many Brazilian regions. Its high vitamin $\mathrm{C}$ content has attracted the interest of consumers, farmers, industries and exporters. Selected materials with desirable characteristics such as high productivity and high fruit quality must be planted to establish new orchards. The main purposes of this work were to estimate and genetically interpret the portion of variability among some characteristics of acerola plants within a population. Open pollination progenies from 62 mother trees previously selected within a commercial plantation were utilized. The experimental design used was a completely randomized block with three replicates, four plants per plot and spacing of 4 by 3 meters. The results showed that in the first year of evaluation the majority of the progenies had already fruited and the proportion of the flowering was lower than that of fruiting during the period of evaluation. The parameters used to evaluate genetic variation within the population showed high variability, which is favorable for selection.

Index terms: Malpighia emarginata, genetic variability, phenotypic selection.

${ }^{1}$ Aceito para publicação em 18 de setembro de 1998.

Trabalho realizado com suporte financeiro do Banco do Nordeste.

${ }^{2}$ Eng. Agr., Ph.D., Embrapa-Centro Nacional de Pesquisa de Agroindústria Tropical (CNPAT), Caixa Postal 3761 , CEP 60511-110 Fortaleza, CE. E-mail: paiva@caju.cnpat.embrapa.br

${ }^{3}$ Eng. Agr., Ph.D. INPA/UFC/Embrapa, Caixa Postal 3761 CEP 60511-110 Fortaleza, CE

${ }^{4}$ Eng. Agr., Embrapa-CNPAT. Bolsistas do CNPq.

\section{INTRODUÇ̃̃OO}

A aceroleira é uma cultura em franca expansão que vem despertando grande interesse por parte de consumidores, produtores, industriais e exportadores, dado o seu alto teor de vitamina C. É uma espécie de fácil propagação pela maioria dos métodos existentes. A propagação sexual tem sido bastante 
empregada no Brasil, apesar dos inconvenientes que apresenta, resultando em plantios altamente heterogêneos, segregação das características da planta e frutos, desuniformidade na produção e na qualidade dos frutos.

No Brasil ainda não existem variedades recomendadas para o plantio comercial, por isso os dados de produção são muito variáveis. Em plantios comerciais, a produção varia de 20 a $50 \mathrm{~kg}$ de frutos/planta/ano (Alves et al., 1995). Em uma das maiores empresas produtoras de acerola, a Companhia de Cítricos do Brasil (CCB), antiga Caju da Bahia S.A. (CAJUBA), a produção média é de $27 \mathrm{~kg} /$ planta/ano (Alves, 1992).

Os fatores que determinam a baixa frutificação desta fruteira são relacionados à dicogamia (principal causa), à falta de pólen viável, a vários tipos de incompatibilidade e formas de heterostilia. A taxa de frutificação de sete clones em regime de polinização aberta no Havaí variou de $1,31 \%$ a $11,58 \%$. Yamane \& Nakasone (1961) sugerem considerável variabilidade genética na habilidade (capacidade) de frutificação de populações de plântulas. A frutificação aumentou de $6,7 \%$ a $55,1 \%$ quando foi feita a autopolinização, provavelmente por causa da alta heterozigosidade das plântulas, ao passo que após a polinização cruzada o incremento foi de $6,66 \%$ a $74,12 \%$. Em todos os casos, a polinização cruzada resultou em taxa de frutificação mais elevada em relação à autopolinização. A causa da baixa frutificação da acerola nas condições climáticas do Havaí foi devida à ausência efetiva do agente polinizador. Grandes plantios de um único clone ou mistura de clones altamente incompatíveis podem reduzir significativamente a produção.

Para a formação de novos pomares, é necessário dispor-se de material selecionado que reúna características favoráveis desejadas, a exemplo de boa formação de copa, tolerância a pragas, a doenças e a nematóides, maior peso, tamanho e número de frutos, coloração vermelho-púrpura, maior conteúdo de vitamina $\mathrm{C}$ e de sólidos solúveis. Nos plantios comerciais, existe variabilidade genética suficiente, que possibilita a identificação de matrizes superiores. Apesar da estreita base genética do material original, a variabilidade genética dos plantios foi altamente amplificada por processo de recombinação genética, que favoreceu o surgimento de novas combinações genéticas.

A seleção de plantas em plantios comerciais temse baseado principalmente nas características da planta (porte e conformação da copa) e do fruto (produção, tamanho, sabor, consistência, coloração e rendimento de polpa) (Bosco et al., 1994; Bezerra et al., 1994). Isto tem ocorrido, provavelmente, devido ao grande número de plantas avaliadas e à dificuldade de efetuarem-se avaliações de outras características em plantios de particulares.

$\mathrm{Na}$ avaliação feita em clones, com número de plantas reduzido, e geralmente, em plantios conduzidos em Estações Experimentais, são considerados também os caracteres relativos ao peso, tamanho e número de frutos, grau Brix, acidez $(\mathrm{pH})$, teor de ácido ascórbico, floração, frutificação, além dos caracteres morfológicos (Yamane \& Nakasone, 1961; Nakasone et al., 1968; Alves \& Menezes, 1994; Bezerra et al., 1994; Gonzaga Neto \& Soares, 1994).

O presente trabalho visou estimar e interpretar geneticamente a variabilidade de alguns caracteres, em uma população de plantas juvenis de acerola obtidas de sementes.

\section{MATERIAL E MÉTODOS}

O experimento foi instalado em área da Estação Experimental de Pacajus, pertencente à Embrapa-Centro Nacional de Pesquisa de Agroindústria Tropical (CNPAT), localizada no município de Pacajus, CE a $4^{\circ} 10^{\prime} \mathrm{S}$ e $38^{\circ} 27^{\prime} \mathrm{W}$, com altitude de $60 \mathrm{~m}$ acima do nível do mar. Utilizaram-se sementes de acerola originadas de plantas selecionadas no plantio comercial da FRUCESA - Frutas do Ceará S/A, localizada no município de Jaguaruana, CE.

$\mathrm{Na}$ seleção fenotípica de plantas no campo, foram consideradas variáveis de fácil mensuração e visualização. A seleção foi feita com base em características da planta e do fruto, direcionadas para conformação da copa, pilosidade nas folhas, tamanho, cor, consistência e sabor do fruto maduro, e estado fitossanitário da planta. As plantas selecionadas foram propagadas sexuadamente.

Inicialmente, as sementes foram postas a germinar em local apropriado, e em seguida procedeu-se à repicagem para sacos de polietileno no viveiro, onde permaneceram por três meses, até o transplantio para o local definitivo.

$\mathrm{O}$ experimento foi instalado no local definitivo em abril/96, sob arranjo experimental de blocos casualizados, 
com 62 tratamentos, três repetições e quatro plantas por parcelas, no espaçamento de $4 \mathrm{~m}$ entre linhas e $3 \mathrm{~m}$ entre plantas. Os tratamentos foram constituídos por progênies de polinização livre, obtidas das plantas selecionadas na FRUCESA.

A avaliação das progênies foi realizada em plantas na fase juvenil, com um ano de idade, mensurando-se os seguintes caracteres: altura da planta, diâmetro do caule a $20 \mathrm{~cm}$ do solo, conformação da copa, e início do florescimento e da frutificação. Na avaliação da conformação da copa, florescimento e frutificação, foram atribuídas as seguintes notas: copa: 1 - aberta, 2 - semi-aberta, 3 - guarda-chuva; florescimento: 1 - planta sem flores, 2 - planta com 1-10 flores, 3 - planta com mais de 10 flores; frutificação: 1 - planta sem fruto; 2 - planta com 1-10 frutos; 3 - planta com mais de 10 frutos.

$\mathrm{Na}$ análise dos dados referentes aos caracteres avaliados por uma escala de notas foi utilizada a transformação $\sqrt{\mathrm{X}+0,5}$. As análises de variâncias referentes a todos os caracteres foram realizadas em plantas individuais dentro de parcelas, utilizando-se do programa GENES (Cruz, 1997). Este programa utiliza as seguintes expressões para estimar os parâmetros genéticos:

$\sigma_{\text {ge }}^{2}=(\mathrm{QMT}-\mathrm{QME}) / \mathrm{rn}$;

$\sigma_{\mathrm{gd}}^{2}=\left(\theta_{\mathrm{d}} / \theta_{\mathrm{e}}\right) \cdot \sigma_{\mathrm{g}}^{2}$;

$\sigma^{2}{ }_{\mathrm{T}}=\sigma_{\mathrm{d}}^{2}+\sigma_{\mathrm{e}}^{2}+\sigma_{\mathrm{g}}^{2}+\sigma_{\mathrm{b}}^{2}$;

$\mathrm{h}^{2}{ }_{\mathrm{e}}=\left(\sigma_{\mathrm{g}}^{2}\right) /(\mathrm{QMT} / \mathrm{nr})$;

$\mathrm{h}_{\mathrm{d}}^{2}=\left(\sigma_{\mathrm{gd}}^{2}\right) /\left(\sigma_{\mathrm{d}}^{2}\right)$;

$\left.\mathrm{h}^{2}=\left(\sigma_{\mathrm{g}}^{2}+\sigma_{\mathrm{gd}}^{2}\right) / \sigma_{\mathrm{d}}^{2}+\sigma_{\mathrm{e}}^{2}+\sigma_{\mathrm{g}}^{2}+\sigma_{\mathrm{b}}^{2}\right)$;

$\mathrm{CV}_{\mathrm{e}} \%=\left(100 \cdot \sqrt{\sigma_{\mathrm{g}}^{2}}\right) / \mathrm{m}$;

$\mathrm{CV}_{\mathrm{g}} \%=\left(100 \cdot \sqrt{\sigma_{\mathrm{gd}}^{2}}\right) / \mathrm{m}$;

$\mathrm{r}_{\mathrm{F}(\mathrm{x}, \mathrm{y})}=\left[\operatorname{Cov}_{\mathrm{F}(\mathrm{x}, \mathrm{y})}\right] /\left[\sigma_{\mathrm{F}(\mathrm{x})}^{2} \cdot \sigma^{2} \mathrm{~F}(\mathrm{y})\right]$;

$\mathrm{r}_{\mathrm{G}(\mathrm{x}, \mathrm{y})}=\left[\operatorname{Cov}_{\mathrm{G}(\mathrm{x}, \mathrm{y})}\right] /\left[\sigma_{\mathrm{G}(\mathrm{x})}^{2} \cdot \sigma_{\mathrm{G}(\mathrm{y})}^{2}\right]$.

Sendo $\sigma_{\text {ge }}^{2}$ - variância genética entre progênies; $\sigma^{2}$ gd - variância genética dentro de progênies; $\sigma^{2}$ fd - variância fenotípica dentro de progênies; $\sigma^{2}{ }_{\mathrm{T}}$ - variância total; $\mathrm{h}_{\mathrm{e}}^{2}$ - herdabilidade entre progênies; $\mathrm{h}_{\mathrm{d}}^{2}$ - herdabilidade dentro de progênies; $\mathrm{h}^{2}$ - herdabilidade ao nível de planta; $\mathrm{CV}_{\mathrm{ge}}$ - coeficiente de variação genética entre progênies; $\mathrm{CV}_{\mathrm{gd}}$ - coeficiente de variação genética dentro de progênies; $b_{1}$ - relação entre o $\mathrm{CV}_{\mathrm{ge}}$ e o $\mathrm{CV}$ experimental; $b_{2}$ - relação entre o $\mathrm{CV}_{\mathrm{gd}}$ e o $\mathrm{CV}$ experimental; QMT - quadradro médio de tratamento; $\mathrm{QME}$ - quadrado médio entre parcelas; $\mathrm{r}_{\mathrm{F}(\mathrm{x}, \mathrm{y})}$ - correlação fenotípica entre as características x e y; $\mathrm{r}_{\mathrm{G}(\mathrm{x}, \mathrm{y})}$ - correlação genética entre as características $\mathrm{x}$ e $\mathrm{y}$.

\section{RESULTADOS E DISCUSSÃO}

Os quadrados médios da análise de variância para todos os caracteres estão apresentados na Tabela 1. Foram detectadas diferenças significativas entre progênies a $1 \%$ de probabilidade referente aos caracteres altura da planta, diâmetro do caule e frutificação, o que indica, já no primeiro ano de idade, que as progênies mostram comportamento diferencial da precocidade na frutificação. Quanto à conformação da copa, foi encontrada diferença significativa somente a $5 \%$ de probabilidade, ao passo que no florescimento, as diferenças foram não-significativas.

Ainda na Tabela 1 estão apresentadas as médias, valores mínimos e máximos das progênies, e coeficiente de variação experimental. Por esses valores pode-se inferir que, com um ano de idade, a maioria das plantas já tinha frutificado, e que no período de avaliação das plantas a proporção de florescimento era menor do que a frutificação. Os coeficientes de variação experimental mantiveram-se em níveis aceitáveis para experimentação de campo, variando de $7,2 \%$ a $13,3 \%$, respectivamente para frutificação e altura da planta.

Na Tabela 2 estão apresentadas a distribuição de freqüências e número de ocorrências de plantas, considerando três classes para cada variável. No que tange aos caracteres altura de planta e diâmetro do caule, a maior freqüência de plantas ocorreu na classe intermediária de variação desses caracteres. Quanto ao caráter conformação da copa, foi encontrada uma freqüência de $43,5 \%$ de plantas que apresentaram o tipo guarda-chuva. As plantas que apresentam essa conformação da copa são mais adequadas à colheita. Este fato é indicativo de que a seleção das plantas matrizes referente a esse caráter foi de certa forma eficiente.

Com um ano de idade das plantas, cerca de $12,8 \%$ delas apresentavam-se em pleno florescimento, sendo que mais da metade $(55,8 \%)$ ainda não tinha florescido. No que respeita à frutificação, entretanto, a maior freqüência de plantas $(59,7 \%)$ foi observada na classe superior, de valores mais próximos à frutificação completa de todas as plantas.

O que se pode observar, em relação ao manejo atual da cultura na região Nordeste, é que as doenças e pragas, até o momento, não são limitantes ao 
desenvolvimento da cultura. Todavia, o nematóide das galhas atualmente é o principal problema. É possível que esta forma de equilíbrio biológico que existe nos plantios comerciais esteja relacionado à forma de propagação sexuada da espécie. Caso isto venha a ser confirmado, é importante que os trabalhos de melhoramento genético da espécie voltados para a obtenção de clones, ou seja, em direção à uniformidade genética dos plantios, encontre formas de representar a diversidade genética existente nesses plantios para autoproteção do sistema cultural.

As estimativas dos componentes da variância para todos os caracteres estão apresentadas na Tabela 3. Os valores da variância genética dentro de progênies, referentes aos caracteres altura de plantas, diâmetro do caule, conformação da copa e frutificação, foram superiores aos existentes entre as progênies. A variância genética entre progênies representa somente cerca de $33 \%$ da variação genética contida dentro das progênies. Estes valores situam-se na faixa intermediária entre os estimados quanto à variância genética entre progênies, em relação à variância dentro de progênies de famílias de meiosirmãos e irmãos germanos, com valores representando cerca de $14 \%$ e $60 \%$, respectivamente (Vencovsky, 1978). No que se refere ao caráter florescimento, as estimativas das variâncias genéticas entre e dentro de progênies apresentaram valores negativos, porém próximos de zero.

Pelas estimativas dos coeficientes de herdabilidade de todos os caracteres, com exceção do florescimento, pode-se afirmar que a seleção de progênies terá ganhos superiores em relação à seleção de plantas dentro de progênies, ou seja, com um ano de idade das plantas a seleção entre é mais favorável do que a seleção dentro de progênies. Por outro lado, os valores dos coeficientes de variação genética dentro de progênies mostram altos conteúdos de variabilidade genética em relação aos coeficientes estimados entre progênies. Os índices $b_{1}$ e $b_{2}$, que quantificam a relação da variação genética perante a variação ambiental entre e dentro de progênies, respectivamente, revelam uma condição mais favorável para a seleção dentro de progênies, principalmente no que se refere à altura da planta, ao diâmetro do caule, e à frutificação.

As estimativas dos coeficientes de correlação genética e fenotípica entre os caracteres de diâmetro do caule e altura da planta foram relativamente baixas e positivas, respectivamente $19,24 \%$ e $29,17 \%$, enquanto entre os caracteres de altura da planta e conformação da copa foram também baixas e negativas. É compreensível essa correlação negativa em acerola, considerando que o ideótipo de planta para o cultivo comercial é conformação de copa tipo "guarda-chuva" e altura da planta reduzida para facilitar a colheita.

Em espécies que se propagam tanto por via sexuada como assexuada, há possibilidade de o melhoramento genético utilizar duas estratégias: seleção de plantas mediante teste de progênies e seleção de plantas com propagação vegetativa

TABELA 1. Quadrados médios de progênies (QMp), do erro entre (QMe) e dentro (QMd) com respectivas significâncias, média e coeficiente de variação experimental (CV) quanto a altura da planta (ALT), diâmetro do caule (DC), conformação da copa (CC), florescimento (FLOR) e frutificação (FRUT).

\begin{tabular}{|c|c|c|c|c|c|}
\hline Parâmetros & $\operatorname{ALT}(\mathrm{m})$ & $\mathrm{DC}(\mathrm{cm})$ & $\mathrm{CC}$ & FLOR & FRUT \\
\hline QMp & $0,1325^{* *}$ & $0,2422 * *$ & $0,0820 *$ & $0,0678^{\mathrm{ns}}$ & $0,0946^{* *}$ \\
\hline QMe & 0,0856 & 0,1647 & 0,0608 & 0,0709 & 0,0602 \\
\hline QMd & 0,0697 & 0,1083 & 0,0380 & 0,0437 & 0,0487 \\
\hline Média & 1,09 & 2,07 & 2,31 & 1,57 & 2,44 \\
\hline CV (\%) & 13,3 & 9,8 & 7,4 & 9,4 & 7,2 \\
\hline Valor mínimo & 0,35 & 0,84 & 1,0 & 1,0 & 1,0 \\
\hline Valor máximo & 2,2 & 3,31 & 3,0 & 3,0 & 3,0 \\
\hline
\end{tabular}


TABELA 2. Distribuição de freqüências de plantas em progênies de acerola quanto a alguns caracteres de plantas com um ano de idade.

\begin{tabular}{ccc}
\hline Variáveis ${ }^{1}$ e classes & $\begin{array}{c}\text { Número de } \\
\text { plantas }\end{array}$ & $\begin{array}{c}\text { Freqüência } \\
(\%)\end{array}$ \\
\hline Altura de planta (m) & & \\
$0,35-0,97$ & 253 & 34,0 \\
$0,97-1,58$ & 448 & 60,2 \\
$1,58-2,20$ & 43 & 5,8 \\
Diâmetro do caule (cm) & & \\
$0,84-1,66$ & 96 & 12,9 \\
$1,66-2,49$ & 567 & 76,2 \\
$2,49-3,31$ & 81 & 10,9 \\
Conformação da copa & & \\
$1,00-1,67$ & 96 & 12,9 \\
$1,67-2,33$ & 324 & 43,5 \\
$2,33-3,00$ & 324 & 43,5 \\
Florescimento & & \\
$1,00-1,67$ & 415 & 55,8 \\
$1,67-2,33$ & 234 & 31,4 \\
$2,33-3,00$ & 95 & 12,8 \\
Frutificação & & \\
$1,00-1,67$ & 110 & 14,8 \\
$1,67-2,33$ & 190 & 25,5 \\
$2,33-3,00$ & 444 & 59,7 \\
\hline
\end{tabular}

${ }^{1}$ Copa: 1 - aberta, 2 - semi-aberta, 3 - guarda-chuva; florescimento: 1 - planta sem flores, 2 - planta com 1-10 flores, 3 - planta com mais de 10 flores; frutificação: 1 - planta sem fruto; 2 - planta com 1-10 frutos;

3 - planta com mais de 10 frutos. (avaliação clonal). Paiva et al. (1982), estimaram o progresso genético de um método de seleção que se utiliza de propagação vegetativa, encontrando maior progresso nesse método em face da seleção de progênies e da seleção simultânea entre e dentro de progênies. Nesse método não há necessidade de recombinação genética, e, conseqüentemente, um ciclo de seleção levaria menos tempo, em contrapartida é limitado a um ciclo de seleção. O maior progresso é devido à exploração adicional da variância genética dominante.

No programa de melhoramento genético de acerola em desenvolvimento no CNPAT é possível a utilização da seleção clonal e do melhoramento populacional. Esses métodos teriam como vantagens a obtenção de clones no curto prazo para atender as demandas imediatas do setor produtivo e, paralelamente, manter em andamento uma linha de pesquisa alternativa para obtenção de resultados a médio e longo prazos.

O melhoramento populacional seria utilizado como prevenção aos problemas que possam ocorrer pela futura massificação do plantio de clones. O plantio de clones conduz à uniformidade e a um maior progresso genético, mas a uniformidade também pode conduzir ao fracasso. A estratégia de melhoramento populacional resultaria na obtenção de semen-

TABELA 3. Componentes de variação da altura de planta (ALT), diâmetro do caule (DC), conformação da copa (CC), florescimento (FLOR) e frutificação (FRUT) em progênies de acerola com um ano de idade.

\begin{tabular}{|c|c|c|c|c|c|}
\hline $\begin{array}{l}\text { Componentes } \\
\text { de variação }\end{array}$ & ALT & $\mathrm{DC}$ & $\mathrm{CC}$ & FLOR & FRUT \\
\hline$\sigma_{\mathrm{ge}}^{2}$ & 0,0039 & 0,0064 & 0,0018 & $-0,0003$ & 0,0029 \\
\hline$\sigma_{\mathrm{gd}}^{2}$ & 0,0117 & 0,0193 & 0,0053 & $-0,0008$ & 0,0086 \\
\hline$\sigma_{\mathrm{fd}}^{2}$ & 0,0697 & 0,1083 & 0,0380 & 0,0437 & 0,0487 \\
\hline$\sigma_{T}^{2}$ & 0,0816 & 0,1325 & 0,0479 & 0,0593 & 0,0554 \\
\hline$h_{e}^{2}$ & 0,35 & 0,32 & 0,26 & $-0,04$ & 0,36 \\
\hline$h_{d}^{2}$ & 0,17 & 0,18 & 0,14 & $-0,01$ & 0,18 \\
\hline$h^{2}$ & 0,19 & 0,19 & 0,15 & $-0,02$ & 0,21 \\
\hline $\mathrm{CV}_{\mathrm{ge}}$ & 5,71 & 3,88 & 2,53 & 0,00 & 3,15 \\
\hline $\mathrm{CV}_{\mathrm{gd}}$ & 9,88 & 6,72 & 4,38 & 0,00 & 5,46 \\
\hline$b_{1}$ & 0,99 & 0,68 & 0,55 & 0,00 & 1,00 \\
\hline $\mathrm{b}_{2}$ & 1,72 & 1,17 & 0,96 & 0,00 & 1,73 \\
\hline
\end{tabular}

$\sigma^{2}$ - variância genética entre progênies; $\sigma^{2}{ }_{g d}$ - variância genética dentro de progênies; $\sigma_{\mathrm{fd}}^{2}$ - variância fenotípica dentro de progênies; $\sigma_{\mathrm{T}}^{2}$ - variância total; $\mathrm{h}_{\mathrm{e}}{ }_{\mathrm{e}}$ - herdabilidade entre progênies; $\mathrm{h}^{2}{ }_{\mathrm{d}}$ - herdabilidade dentro de progênies; $\mathrm{h}^{2}=$ herdabilidade ao nível de planta; $\mathrm{CV}_{\mathrm{ge}}$ - coeficiente de variação genética entre progênies; $\mathrm{CV}_{\mathrm{gd}}$ - coeficiente de variação genética dentro de progênies; $b_{1}$ - relação entre o $\mathrm{CV}_{\mathrm{ge}} \mathrm{e}$ o $\mathrm{CV}$ experimental; $\mathrm{b}_{2}$ - relação entre o $\mathrm{CV}_{\mathrm{gd}}$ e o $\mathrm{CV}$ experimental. 
tes melhoradas de aceroleira para o plantio comercial. Possivelmente, ocorreria redução da produtividade de frutos em relação ao plantio de clones, mas com a garantia de redução também dos problemas fitossanitários.

\section{CONCLUSÕES}

1. Pelas estimativas dos coeficientes de herdabilidade a seleção de progênies resulta em ganhos superiores em relação à seleção de plantas dentro de progênies.

2. A freqüência de plantas que apresenta a conformação da copa "guarda-chuva" na geração filial é elevada, demonstrando que a seleção massal das plantas matrizes para esse caráter é eficiente.

3. Os índices $b_{1}$ e $b_{2}$ revelam uma condição favorável à seleção dentro de progênies.

\section{REFERÊNCIAS}

ALVES, R.E. Cultura da acerola. In: DONADIO, L.C.; MARTINS, A.B.G.; VALENTE, J.P. (Eds.). Fruticultura tropical. Jaboticabal: FCAV/FUNEP/UNESP, 1992. p.15-37.

ALVES, R.E.; MENEZES, J.B. Caracterização pós-colheita de acerolas vermelhas e amarelas colhidas em pomar comercial. In: CONGRESSO BRASILEIRO DE FRUTICULTURA, 13., 1994, Salvador. Anais... Salvador: SBF, 1994. p.99-100.

ALVES, R.E.; MENEZES, J.B.; SILVA, S.M. Colheita e pós-colheita da acerola. In: SÃO JOSÉ, A.R.; ALVES, R.E. Acerola no Brasil: produção e mercado. Vitória da Conquista: DFZ/UESB, 1995. p.77-89.
BEZERRA, J.E.F.; LEDERMAN, I.E.; CARVALHO, P.S.; MELO NETO, M.L. Avaliação de clones de aceroleira na região do vale do rio Moxotó-PE. I - Plantas juvenis In: CONGRESSO BRASILEIRO DE FRUTICULTURA, 13., 1994, Salvador. Anais... Salvador: SBF, 1994. p.85-86.

BOSCO, J.; AGUIAR FILHO, S.P.; BARREIRO NETO, M. Características fenológicas de plantas de aceroleira. In: CONGRESSO BRASILEIRO DE FRUTICULTURA, 13., 1994, Salvador. Anais... Salvador: SBF, 1994. p.87-88.

CRUZ, C.D. Programa GENES: aplicativo computacional em genética e estatística. Viçosa: UFV, 1997. 442p.

GONZAGA NETO, L.; SOARES, J.M. Acerola para exportação: aspectos técnicos da produção. Brasília: FRUPEX/MAARA/EMBRAPA-SPI, 1994. 43p. (FRUPEX. Publicações Técnicas, 10).

NAKASONE, H.Y.; YAMANE, G.M.; MIYASHITA, R.K. Selection, evaluation, and naming of acerola (M. glabra L.) cultivars. Honolulu: Hawaii Agricultural Experiment Station, 1968. 19p. (Circular, 65).

PAIVA, J.R.; MIRANDA FILHO, J.B.; SIQUEIRA, E.R.; VALOIS, A.C.C. Predição do ganho genético de alguns caracteres em seringueira em três esquemas de seleção. Pesquisa Agropecuária Brasileira, Brasília, v.17, n.11, p.1647-1653, 1982.

VENCOVSKY, R. Herança quantitativa. In: PATERNIANI, E. (Ed.). Melhoramento e produção do milho no Brasil. Piracicaba: USP/ESALQ, 1978. cap.5, p.122-201.

YAMANE, G. M.; NAKASONE, H.Y. Pollination and fruit set studies of Acerola (Malpighia glabra L.) in Hawaii. Proceedings of the American Society for Horticultural Science, Beltsville, v.78, p.141-148, 1961. 